\title{
ZONEAMENTO GEOAMBIENTAL DA SUB-BACIA HIDROGRÁFICA DO RIO MANDU, SUL DE MINAS GERAIS, PELA GEOECOLOGIA DAS PAISAGENS
}

\author{
GEOENVIRONMENTAL ZONING OF THE RIVER MANDU WATERSHED, SOUTH OF MINAS \\ GERAIS, BY THE GEOECOLOGY OF LANDSCAPES
}

\author{
Gustavo Costa TEIXEIRA ${ }^{1}$, André dos Santos RIBEIRO ${ }^{2}$, Ronaldo Luiz MINCATO ${ }^{3}$ \\ ${ }^{1}$ Mestre em Ciências Ambientais pela Universidade Federal de Alfenas, Alfenas, Minas Gerais. Email: gustavo.costa.t@hotmail.com \\ ${ }^{2}$ Mestre em Ecologia e Tecnologia Ambiental pela UNIFAL-MG e Docente do Centro de Ensino Superior em Gestão, Tecnologia e \\ Educação, Santa Rita do Sapucaí, Minas Gerais. Email: andreribeiro@fai-mg.br \\ ${ }^{3}$ Docente do Programa de Pós-Graduação em Ciências Ambientais, Instituto de Ciências da Natureza, Universidade Federal de \\ Alfenas, Alfenas, Minas Gerais. Email: ronaldo.mincato@unifal-mg.edu.br
}

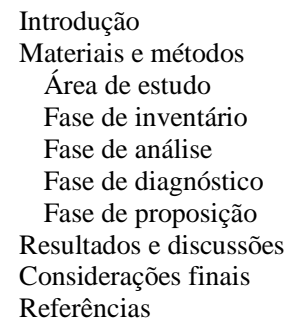

RESUMO - O atual processo de acelerada urbanização, de concentração de pessoas e de atividades econômicas no Brasil causa pressões, altera e impacta de forma deletéria e direta os diferentes ambientes locais, especialmente as sub-bacias hidrográficas. Neste cenário, foi elaborado o Zoneamento Geoambiental da Sub-Bacia Hidrográfica do Rio Mandu, na Região Sul do Estado de Minas Gerais. O trabalho foi feito a partir da concepção de Geoecologia das Paisagens, baseada no conceito de geossistemas, no qual a paisagem é estudada sob perspectiva sistêmica, que considera as relações entre natureza, economia, sociedade e cultura. A partir dos pressupostos teórico-metodológicos adotados, foi possível identificar a localização e caracterizar a adequação dos usos antrópicos frente ao sistema ambiental natural. A partir daí, foram estabelecidas as bases para proposições sobre a gestão ambiental da paisagem local com vistas à sustentabilidade, por meio de indicações de alternativas de usos adequados dos recursos naturais.

Palavras-chave: Geoprocessamento, Geossistema, Planejamento Ambiental, Rio Grande.

\begin{abstract}
The present process of rapid urbanization and concentration of people and economic activities in Brazil causes pressures and changes, and impacts, in a harmful and direct way, local environments, mainly watersheds. In this scenario, the Geoenvironmental Zoning of Rio Mandu Watershed, south of Minas Gerais, was carried out. The Geoecology of Landscapes design, based on the concept of geosystems, in which the landscape is studied from the systemic perspective, considering the relationship between nature, economy, society and culture, was used. From the adopted methodological-theoretical assumptions, it was possible to identify the location and characterize the suitability of the anthropic uses having in mind the natural environmental system. From then on, the bases for consideration of the environmental management of the local landscape for sustainability through propositions of appropriate uses of natural resources were established.
\end{abstract}

Keywords: Geoprocessing, Geosystem, Environmental Planning, Rio Grande.

\section{INTRODUÇÃO}

No atual cenário de substanciais alterações estruturais promovidas pelas atividades antrópicas nos sistemas ambientais, de desperdício dos recursos naturais e de degradação generalizada, com efeitos na perda de qualidade de vida e do meio ambiente, é, cada vez mais, imperativo o planejamento físico-territorial não apenas da perspectiva econômica e social, mas também ambiental.

Assim, os objetivos dos planejadores, dos políticos e da sociedade em geral deveriam ultrapassar os limites dos interesses de desenvolvimento econômico e tecnológico e focarem na sustentabilidade do desenvolvimento, contemplando tanto as potencialidades da população e dos recursos naturais, como as fragilidades dos ambientes naturais diante das intervenções antrópicas (Ross, 2009).

No contexto dos sistemas ambientais brasileiros, diante das alterações antrópicas e da degradação ambiental, o Sistema Nacional de Unidades de Conservação (SNUC) trouxe importantes contribuições quanto à preservação e proteção de áreas de elevado interesse ambiental (Brasil, 2011). Previstas neste aparato legal, as Áreas de Preservação Permanente (APP) e as Áreas de Proteção Ambiental (APA) e de Reserva Legal (RL) são umas das formas válidas de gerenciamento dos recursos naturais. Em geral, ao respeitar os processos naturais, estas áreas protegem a diversidade biológica e os serviços ecossistêmicos, disciplinam o processo de 
ocupação e asseguram o uso sustentável dos recursos naturais (Brasil, 2011).

Por definição, as APA são áreas, em geral, extensas, com ocupação humana e dotadas de atributos abióticos, bióticos, estéticos e culturais, especialmente importantes para a qualidade de vida e o bem-estar das populações humanas (Brasil, 2011). Já as APP, conforme o Código Florestal (Brasil, 2012), são áreas protegidas, cobertas ou não por mata nativa, com a função ambiental de preservar os recursos hídricos, a paisagem, a estabilidade geológica, a biodiversidade, o fluxo gênico da fauna e da flora, proteger o solo e assegurar o bem-estar das populações humanas.

Ainda, a RL é uma área no interior de uma propriedade rural coberta com vegetação nativa ou nativa e exótica, que visa assegurar o uso econômico sustentável dos recursos naturais, auxiliar a conservação e recuperação dos processos ecológicos, promover a conservação da biodiversidade, bem como o abrigo e a proteção de fauna silvestre e da flora nativa e assegurar e preservar o bem-estar das populações humanas.

As normas previstas no SNUC amparam a melhoria do aproveitamento do espaço e dos recursos naturais. No mesmo sentido, o Decreto Federal $\mathrm{N}^{\circ} 4.297 / 2002$, que regulamentou o Zoneamento Ambiental como parte da Política Nacional de Meio Ambiente, visa promover a ocupação e os usos dos recursos naturais com a minimização de impactos.

Este aparato legal foi sustentado por diversas delimitações e proposições teóricas, metodológicas e aplicadas. Para Rodrigues (2001), em relação à organização do território, tais concepções tiveram suporte teórico dado pela Teoria Geral dos Sistemas, com considerações trabalhadas por Bertrand (1971), Tricard (1977) e Sotchava (1977), que incorporaram conceitos sobre sistemas ambientais, amplamente usados e muito adotados em pesquisas no Brasil.

A partir da Teoria Geral dos Sistemas, baseada na concepção de geossistemas como formações terrestres complexas e hierarquicamente organizadas, Rodriguez et al. (2007) propuseram a Geoecologia da Paisagem, que considera a interação natureza - sociedade em seus aspectos estruturais e funcionais. Para Gigliotti (2010), a Geoecologia da Paisagem é a base para o planejamento ecológico do território e visa, não somente descrever a partir da observação, mas explicar as conexões e influências entre os processos naturais e humanos. Para tanto, a visão de paisagem como formação antroponatural visa identificar a relação entre os efeitos das ações humanas em um sistema natural de processo-resposta.

Assim, Rodriguez et al. (2007) definiram os princípios básicos da Geoecologia da Paisagem. O princípio geossistêmico concebe a paisagem natural como um sistema ambiental aberto, complexo, formado por componentes e complexos de diferentes níveis, compostos pela influência dos processos naturais e das atividades transformadoras da sociedade humana, formando um sistema integrado. Decorre, portanto, da existência objetiva da paisagem, como geossistema e não como uma abstração.

Outro princípio é o da articulação sistêmica e paisagística, no qual a paisagem é formada pela tríade: paisagem natural/paisagem social/paisagem cultural. Este princípio aproxima a percepção de espaço geográfico, território e paisagem à noção de meio ambiente, a fim de superar a dicotomia natureza e sociedade. Ademais, estrutura, funcionamento, dinâmica e evolução são atributos sistêmicos da paisagem natural que constituem a base teórica e metodológica, que possibilita discutir a paisagem como um todo. Por fim, a paisagem também possui valor social e cada paisagem tem um potencial para efetuar determinadas atividades produtivas, que repercute no possível cumprimento de determinadas funções socioeconômicas.

Além dos princípios básicos, também foram delimitados os procedimentos da Geoecologia da Paisagem, divididos por Rodriguez et al. (2007) em 6 fases: (1) Fase de Organização, em que são definidos os objetivos da pesquisa, é delimitada a área e apresentado o projeto de pesquisa; (2) Fase de Inventário, em que é feita a caracterização física e do uso antrópico da área, pela elaboração dos mapas de declividade, hipsométrico, geológico, pedológico, geomorfológico e de usos do solo; (3) Fase de Análise, em que são correlacionadas as informações obtidas na etapa anterior e gerados os mapas de Geossistemas e de Sistemas Antropo-Naturais; (4) Fase de Diagnóstico, em 
que é caracterizada a situação ambiental, pelo Mapa de Estado Ambiental, e o diagnóstico integrado pelo Mapa de Unidades Geoambientais; (5) Fase de Proposição, em que é feita a síntese das fases prévias no Zoneamento Geoambiental; e, por fim, (6) Fase de Execução, em que é executado o Zoneamento Geoambiental proposto.

Esta pesquisa foi desenvolvida até a fase (5) de Proposição. Pois, a última fase, é de competência da administração pública. Todavia, para implementação deste planejamento pelo poder público alguns requisitos são essenciais, como: a reflexão sobre o modelo de desenvolvimento a ser adotado e a instrumentação jurídica, administrativa e financeira. A partir de então, é preciso definir estratégias de regulação, controle e correção e mecanismos de gestão, ligados a sistemas de informação para monitoramento e fiscalização, em parceria com o comitê de bacia hidrográfica e com instituições estaduais e federais incumbidas da questão ambiental.

Para execução das fases detalhadas, os conceitos sobre função geoecológica dos geossistemas, estado ambiental, unidades geoambientais e zoneamento geoambiental são essenciais. Para Rodriguez (1994), a função geoecológica do geossistema é definida pelo objetivo que cumpre o sistema em garantir sua estrutura e funcionamento e do sistema superior ao qual pertence. Assim, como produto analítico característico da metodologia, as funções geoecológicas dos geossistemas foram classificadas qualitativamente em: (a) Áreas Emissoras: que garantem o fluxo de matéria e energia, sendo assim, por exemplo, os locais mais elevados do terreno; (b) Áreas Transmissoras: em que predomina o transporte dos fluxos de matéria e energia das áreas mais elevadas para as mais baixas, como, por exemplo, as encostas e (c) Áreas Acumuladoras: onde ocorre a coleta da matéria e energia oriundas das áreas mais elevadas, que são concentradas, armazenadas, absorvidas, filtradas e retransmitidas, pelos canais fluviais. Exemplos são os fundos de vale e as planícies.

Outro aspecto da Geoecologia da Paisagem é o diagnóstico do estado ambiental. Para tanto, Gigliotti (2010) assinalou que as mudanças dos mecanismos de formação e regulação sistêmica, o grau e amplitude dos processos degradantes e o nível de degradação determinam o estado ambiental do geossistema. Portanto, deve ser considerado o tipo, o grau de impacto e a capacidade de reação e absorção do geossistema (Rodriguez et al., 2007).

Para caracterização do estado ambiental dos geossistemas, Rodriguez \& Martinez (1998) e Glazovskiy et al. (1998), conforme Rodriguez et al. (2007), apresentaram uma classificação em cinco níveis: (1) Estável: estado não alterado, no qual a estrutura original é conservada e não há problemas ambientais significativos que deteriorem a paisagem. Os processos geoecológicos têm caráter natural e a influência antrópica é pouco significativa; (2) Medianamente estável: estado sustentável com poucas alterações estruturais e apenas alguns problemas de intensidade leve a moderada, que não modificam $o$ potencial natural e a integridade do geossistema. São áreas desenvolvidas e utilizadas pelo homem, de forma balanceada com o seu potencial e pode ser sustentado por várias gerações. Estas áreas necessitam de conservação de baixo custo e cuidados para a manutenção da sustentabilidade; (3) Instável: estado insustentável, no qual parte do sistema natural conserva sua integridade. No entanto, fortes mudanças de estrutura espacial e funcional impedem o desempenho de suas funções geoecológicas. $\mathrm{O}$ surgimento de problemas ambientais como resultado da exploração dos recursos é causa do declínio da produtividade, que no curso de uma geração pode ser comprometida; (4) Crítico: áreas com perda parcial das estruturas espacial e funcional, com supressão paulatina das funções geoecológicas. Neste, o uso dos solos e o impacto das atividades antrópicas superaram a capacidade de suporte dos sistemas naturais. Há drástica redução do potencial da terra. As paisagens precisam de medidas de mitigação urgentes para retomada do potencial natural, o que demanda, no mínimo, o tempo de uma geração para a recuperação dos processos geoecológicos; e (5) Muito crítico: áreas com perda e alteração generalizada da estrutura espacial e funcional, que impede o sistema natural de cumprir as funções geoecológicas e com expressivos problemas ambientais de intensidade forte, sendo impróprias para uso humano. 
Assim como o Mapa de Estado Ambiental, Rodriguez et al. (2007) destacam, ainda na fase de diagnóstico, a elaboração do Mapa de Unidades Geoambientais. Deste modo, definem unidades geoecológicas ou geoambientais como a individualização e tipologia de unidades de paisagem, que nos estudos locais tratam das propriedades topológicas e morfológicas de diferenciação paisagística. Pois as paisagens podem ser classificadas conforme a estrutura morfológica, a gênese, a designação e as possibilidades de utilização funcional. Assim, a tipologia geoecológica ou de paisagens é feita pela análise, classificação e cartografia dos "complexos físico-geográficos tipológicos" naturais e antropizados, com vistas à compreensão de sua composição, estrutura, relações, desenvolvimento e diferenciação (Rodriguez et al., 2007).

\section{MATERIAIS E MÉTODOS}

\section{Área de Estudo}

A Sub-bacia Hidrográfica do Rio Mandu é uma área com cerca de $500 \mathrm{~km}^{2}$ na Região Sul de Minas Gerais e pertence a Sub-bacia Hidrográfica do Rio Sapucaí, que é afluente do Rio Grande. Abrange parte dos Municípios de Borda da Mata,
Obtido da correlação entre o grau de estabilidade das unidades geoambientais e a dinâmica de funcionamento ambiental, o Zoneamento Geoambiental é uma síntese com propostas de usos adequados para cada fração da paisagem. Permite definir zonas para conservação, preservação, melhoramento, reabilitação ambiental e para o desenvolvimento local, que, aliadas à legislação, permitem a determinação de funcionalidades de acordo com as características da paisagem.

Diante deste contexto, este trabalho apresenta uma proposta de Zoneamento Geoambiental da Sub-bacia Hidrográfica do Rio Mandu, no sul de Minas Gerais, a partir dos procedimentos metodológicos da Geoecologia da Paisagem em escala 1:100.000.

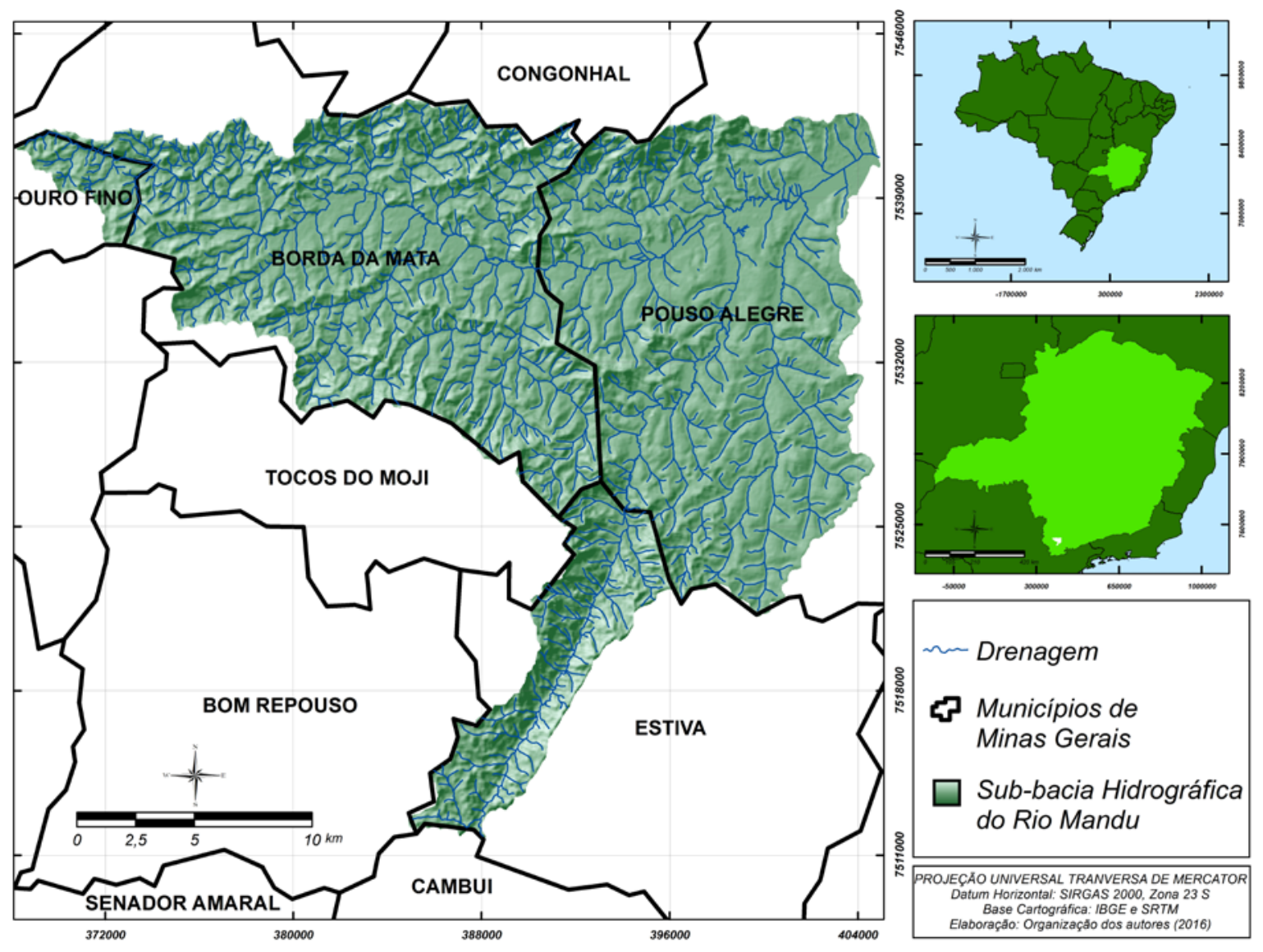

Figura 1 - Mapa de localização da Sub-bacia Hidrográfica do Rio Mandu. 
Com arcabouço geológico composto por complexos granito-gnáissicos do Sistema Orogênico do Tocantins (CPRM, 1998), associada ao clima tropical de altitude Cwa e Cwe (Sparovek et al., 2007), com pluviosidade média anual entre 1.600 e 1.865 mm (Mello et al., 2007), foi desenvolvido o modelado geomorfológico do Domínio das Unidades Denudacionais em Rochas Cristalinas ou Sedimentares, com altitudes entre 816 e $1.482 \mathrm{~m}$ (Machado \& Silva, 2010).

Devido à relativa homogeneidade litológica, o padrão de drenagem dominante é o dendrítico com canais de $1^{\mathrm{a}}$ e $2^{\mathrm{a}}$ ordens com orientação NNE-SSW e de 3 e $4^{\text {a }}$ ordens com direção NESW (Magalhães Jr. \& Diniz, 1997), mas com direção geral W-E. De acordo com Magalhães Jr. \& Diniz (2005), a maioria dos vales de afluentes do rio Sapucaí estão escavados ao longo de falhamentos transcorrentes regionais, como o vale do Rio Mandu nas falhas de Borda da Mata e Monte Sião, com direção WSW-ENE e condicionado pelo Cinturão de Cisalhamento Ouro Fino.

\section{Fase de Organização}

Inicialmente, foram definidos os objetivos da pesquisa, a partir do roteiro de Rodriguez et al. (2007), e definidas as características físicas e de uso do solo da área. O aplicativo ArcGIS 10.2.2 ${ }^{\circledR}$ (ESRI, 2014) foi utilizado para construção e manipulação do banco de dados georreferenciados.

\section{Fase de Inventário}

O levantamento cartográfico foi feito a partir das cartas topográficas do Instituto Brasileiro de Geografia e Estatística (IBGE, 1971a, b; 1972a, b, c), na escala 1:50.000, folhas Santa Rita de Caldas (SF-23-Y-B-I-1), Ipuiúna (SF-23-Y-B-I2), Borda da Mata (SF-23-Y-B-I-4), Pouso Alegre (SF-23-Y-B-II-1) e Conceição dos Ouros (SF-23-Y-B-II-3). A partir delas foram digitalizadas as drenagem, nascentes e pontos cotados. Além destas, foi usada imagem do sensor Operational Land Imager (OLI) Landsat8, órbita 219 , ponto 75 , de setembro de 2015 , nas bandas espectrais $5(0,85-0,88 \mu \mathrm{m}), 4(0,630-$ $0,680 \mu \mathrm{m}), 3(0,525-0,600 \mu \mathrm{m}), 2(0,450-$ $0,515 \mu \mathrm{m})$ com $30 \mathrm{~m}$ de resolução espacial e 8 pancromática $(0,500-0,680 \mu \mathrm{m})$ com $15 \mathrm{~m}$ de resolução espacial, e o Modelo Digital de Elevação (MDE) Advanced Spaceborne Thermal and Reflection Radiometer Global Digital
Elevation Map (ASTER GDEM) da NASA (2015), com resolução espacial de $30 \mathrm{~m}$.

O levantamento geológico sobre litologia, estratigrafia, geocronologia e arcabouço tectônico, foi realizado a partir do mapa de CPRM (1998), em escala 1:250.000. Para os solos, foi utilizado o mapa de solos da Sub-bacia Hidrográfica do Rio Mandu, em escala 1:100.000 (Ribeiro et al., 2016).

A geomorfologia foi delimitada a partir da vetorização de formas poligonais das áreas de morfologias semelhantes. Desta forma foram mapeadas 8 unidades de relevo.

Para o mapeamento geomorfológico, foi feita a interpretação da rugosidade e textura de composição colorida com imagens do sensor OLI do satélite Landsat-8 nas bandas espectrais 5 R, 4 $\mathrm{G} \quad$ e $\quad 3 \quad \mathrm{~B}$ combinadas às características geométricas da banda 8 pelo processo de fusão disponível no aplicativo ArcGIS 10.2.2 ${ }^{\circledR}$ (ESRI, 2014). Além desta, foi usada a imagem do relevo sombreado do MDE ASTER GDEM. Foram feitas ainda análises morfométricas de Hipsometria, Clinográfica e de Classes de Relevo (Ribeiro et al., 2016), obtidas do MDE ASTER GDEM e de Índices de Dissecação do Relevo, tal como proposto por Ross (1994) a partir das cartas topográficas (IBGE, 1971a, b; 1972a, b, c).

Além destes, foram obtidas informações sobre os aspectos morfotectônicos, morfoestruturais e de padrões de formas de Magalhães Jr. \& Diniz (2005) e Machado \& Silva (2010) e de padrões de drenagem de Magalhães Jr. \& Diniz (1997).

O mapa geomorfológico foi feito conforme a taxonomia de classificação do relevo de Ross (1992), a qual deve ser feita do nível macro para o micro, das grandes estruturas ( $1^{\circ}$ Táxon) até as formas de processos atuais em vertentes $\left(6^{\circ}\right.$ Táxon). Neste caso, foram feitas inferências até o $3^{\circ}$ Táxon, a partir das Unidades Morfoestruturais (1 ${ }^{\circ}$ Táxon), Maciços do Alto Rio Grande e Depressão do Sapucaí. Estas duas unidades foram separadas em quatro Unidades Morfoesculturais ( $2^{\circ}$ Táxon): Domínio dos Sedimentos Indiferenciados da Depressão do Sapucaí, Domínio dos Complexos Granitoides dos Planaltos do Alto Rio Grande, Domínio dos Complexos Metamórficos do Planalto da Mantiqueira e Domínio dos Complexos Metamórficos dos Planaltos do Alto Rio Grande. A partir daí foi elaborada a cartografia síntese de 
Unidades Morfológicas ou de padrões de formas semelhantes ( $3^{\circ}$ Táxon) e foram definidas as 8 subunidades seguintes: Planalto da Mantiqueira, Escarpas do Planalto da Mantiqueira, Cristas e Escarpas Setentrionais, Blocos Serranos Intermediários, Serras Baixas, Morros, Colinas e Planície Fluvial.

Os usos do solo, por sua vez, foram classificados em floresta, uso urbano, agricultura temporária, café, silvicultura, pastagens e solo exposto. Para tanto foi usado o método de segmentação da imagem, com dados obtidos a partir de composição colorida (4R, 3G e 2B) do sensor OLI Landsat-8, na qual foi aplicado o processo de fusão da composição colorida com a banda 8 pancromática para melhorar o detalhamento geométrico, pelo algoritmo do ArcGIS 10.2.2 ${ }^{\circledR}$ (ESRI, 2014). Em seguida, foi aplicada a técnica de classificação por segmentos no aplicativo ENVI 5.0 (2012), com os limiares de nível de escala e nível de dissolução, respectivamente com os valores, 60 e 65 . O desempenho foi aferido, visualmente, julgando o nível de detalhe e as generalizações. Após, foram extraídos os atributos espaciais, espectrais, texturais, de cor e razão de bandas, que serviram de base para classificação dos usos do solo pelo algorítimo SVM (Support Vector Machines).

\section{Fase de Análise}

O Mapa de Geossistemas expressa a síntese dos sistemas naturais e foi feito a partir do mapa geomorfológico. As unidades foram distribuídas de acordo com a dinâmica de fluxo de matéria e energia em três zonas: (1) Zonas Dispersoras: áreas de topos, nas maiores cotas altimétricas, onde há dispersão de matéria e energia. Na área de estudo, envolve as cotas acima de $1.080 \mathrm{~m}$; (2) Zonas Transmissoras: áreas de vertentes, serras baixas, morros e colinas, variando, em declivi-dade, de ondulado a montanhoso, com altitudes entre 1.080 e $860 \mathrm{~m}$, e predomínio da trans-missão de matéria e energia; e (3) Zonas Acumuladoras: áreas de planície fluvial, com altitudes dominantemente abaixo de $860 \mathrm{~m}$ e pouca declividade, que recebem fluxos de matéria e energia.

O Mapa de Sistemas Antropo-Naturais, com a síntese da dinâmica de uso e ocupação, foi obtido pelo mapeamento dos usos do solo e da dinâmica predominante. As remoções e deposições de solos e resíduos por ações humanas também foram consideradas quando adequadas à escala. Tais processos originam depósitos tecnogênicos construídos, classificados de acordo com a composição do material em: gárbicos (lixo orgânico), úrbicos (detritos urbanos e artefatos manufaturados) e espólicos (materiais terrosos cavados e redepositados) (Peloggia, 2005). Assim, foram definidos dois agrupamentos: 1) Sistemas Antrópicos: Comunidades Rurais, Sistemas Agrícolas Permanentes, Sistemas Agrícolas Temporários, Sistemas Pastoris, Sistemas Urbanos e Depósitos Tecnogênicos; e 2) Sistemas Naturais: Sistemas de Formação Florestal.

\section{Fase de Diagnóstico}

Nesta fase foram apontados os locais em que a interação dos fatores uso do solo, dissecação do relevo e tipo de solo condicionam instabilidade em termos de morfodinâmica. Para tanto, foi elaborado o Mapa de Morfodinâmica, feito pelo mapeamento de processos morfodinâmicos de rastejos e ravinas.

Assim, foram identificados os tipos de uso, de solo e de dissecação que tornam o ambiente vulnerável e o potencial à instabilidade foi inferido por lógica booleana, com o algarismo 1 indicando a presença. Desta forma, locais com instabilidade potencial foram aqueles em que as três variáveis, uso (1), solo (1) e dissecação (1), são simultaneamente vulneráveis. As áreas com as demais combinações foram julgadas estáveis.

Em seguida, foram identificadas as interações entre geossistema, instabilidade morfodinâmica e sistemas antropo-naturais de usos do solo e foi obtido o Mapa de Estado Ambiental com cinco classes qualitativas, conforme Rodriguez et al. (2007), de Estável e Muito Crítico. Para tanto, os arquivos vetoriais dos planos geossistema, morfodinâmica e sistemas antropo-naturais foram unidos em um mesmo mapa e tabela pela ferramenta Union e seus atributos alfanuméricos foram agrupados pela ferramenta Dissolve no aplicativo ArcGIS 10.2.2 ${ }^{\circledR}$ (ESRI, 2014). Assim, para cada agrupamento de características, foi definido um estado ambiental.

Na sequência, para produzir o Mapa de Unidades Geoambientais foram empregadas as interações entre geomorfologia e os sistemas antropo-naturais. Tecnicamente, foi usado o mesmo procedimento utilizado para unir os 
arquivos vetoriais. Portanto, além das oito unidades de relevo, foram identificadas 22 sub-unidades associando relevo aos usos dos solos.

\section{Fase de Proposição}

O Zoneamento Geoambiental da Sub-bacia Hidrográfica do Rio Mandu foi feito a partir da interação entre as unidades geossistêmicas, as unidades geoambientais, o estado ambiental com a legislação vigente sobre ordenamento do uso do solo da área, desde a federal (Brasil, 2012) até a municipal (Pouso Alegre, 2008).
A execução do mapeamento das zonas geoambientais foi possível, novamente, com a união dos arquivos vetoriais e o agrupamento dos atributos alfanuméricos numa única tabela. Aliando a combinação entre uso e ocupação do solo a proposições sobre a preservação dos recursos naturais, foram identificadas 5 zonas na sub-bacia: 1) Zonas de Proteção Ambiental, 2) Zonas de Conservação Ambiental, 3) Zonas de Melhoramento Ambiental, 4) Zonas de Conservação e Estímulo ao Desenvolvimento Local e 5) Zonas de Reabilitação Ambiental.

\section{RESULTADOS E DISCUSSÕES}

Como recomendado por Dias \& Oliveira (2012), a demarcação de áreas com certa homogeneidade nos aspectos físicos da paisagem foi feita usando, em primeiro plano, a compartimentação geomorfológica, com síntese sobre os componentes endógenos e exógenos.

Magalhães Jr. \& Diniz (2005) descreveram, genericamente, os padrões de formas de relevo na sub-bacia. Para os autores, a configuração geomorfológica atual resulta dos eventos de soerguimento da cunha tectônica de Socorro, que acondicionou os desníveis da borda sul, o soerguimento da Serra do Descalvado, que condicionou os conjuntos serranos da margem norte, e a formação do Graben do Rio Mandu, que resultou na configuração de patamares rebaixados, terraços e a várzea da paisagem local. Os autores descrevem a ocorrência de morros e blocos serranos divisores entre as subbacias dos rios Mandu e do Cervo na porção setentrional, na margem norte do rio. Já na margem sul, no alto e médio curso, ocorrem cristas e vertentes orientadas pelo forte controle estrutural, com predomínio de serras e interflúvios estreitos e alongados na direção N$\mathrm{S}$ com vertentes abruptas.

Nos limites meridionais ocorrem serras que constituem divisores entre as sub-bacias dos rios Mandu e Mogi Guaçu, com desníveis de até $300 \mathrm{~m}$. Também na margem sul, é destacado o "Canyon" do Ribeirão do Pântano, braço anômalo com cerca de $35 \mathrm{~km}$ de comprimento na direção NNE-SSW, rumo à bacia do rio Mogi Guaçu. O vale possui perfil longitudinal com sucessivos degraus topográficos e foi esculpido ao longo da Falha de Senador Amaral (Magalhães Jr. \& Diniz, 2005).

Nos setores mais suavizados do relevo,
Magalhães Jr. \& Diniz (2005) descrevem patamares rebaixados na margem direita do baixo curso da sub-bacia, predominando formas com interflúvios largos e alongados na direção $\mathrm{N}-\mathrm{S}$, com topos aplainados. Para eles, nas margens do Rio Mandu, principalmente a direita, há ocorrência de quatro níveis de terraços, um no nível de várzea, e os outros, inferior, intermediário e superior, com desnível médio de 0 a 10 metros em relação à calha.

Tais descrições, aliadas aos produtos cartográficos, possibilitaram a discriminação das unidades geomorfológicas, usadas para explicar a dinâmica natural da Sub-bacia Hidrográfica do Rio Mandu, considerada como um arranjo de geossistemas conectados entre si. O Mapa de Geossistemas (Figura 2) ilustra a análise feita, do tipo processo-resposta, de acordo com a dinâmica de fluxo de matéria e energia, de morfogênese $e$ as formas resultantes.

Em geral, o relevo da sub-bacia é mais dissecado nas áreas com embasamento mais intensamente deformado, sendo estas as Zonas Dispersoras e Transmissoras. Quanto às áreas com menor intensidade de dissecação, há correlação com embasamento geológico mais recente de depósitos sedimentares fluviais e depósitos indiferenciados, do Cenozoico.

As Zonas Dispersoras, que garantem o fluxo de matéria e energia para o restante da subbacia, representam os topos dos relevos mais elevados, convexos e com altitudes entre 1.080 e $1.482 \mathrm{~m}$. Nestas zonas, o substrato é de idade Arqueana à Proterozoica, com unidades de metaconglomerados, gnáissicas, graníticas e migmatíticas (CPRM, 1998). Quanto aos solos, os horizontes superficiais são argilosos e os 
perfis variam de rasos a razoavelmente profundos com ocorrência de cambissolos e argissolos (Ribeiro et al., 2016).

As Zonas Transmissoras, com domínio do transporte dos fluxos de matéria e energia, exibem declividades e altitudes que variam de acordo com o tipo de relevo, condicionado pelas falhas no embasamento cristalino.

As Vertentes dos Blocos Serranos Interme- diários, das Cristas e Escarpas Setentrionais e das Escarpas do Planalto da Mantiqueira, são as encostas mais íngremes da sub-bacia, consideradas montanhosas pela predominância de declives acima de $45 \%$, enquanto as Serras Baixas, com declividade predominante entre 20 e 45\%, são de relevo intermediário. Já as Colinas e Morros são os relevos rebaixados, com declividades entre 8 e $20 \%$.

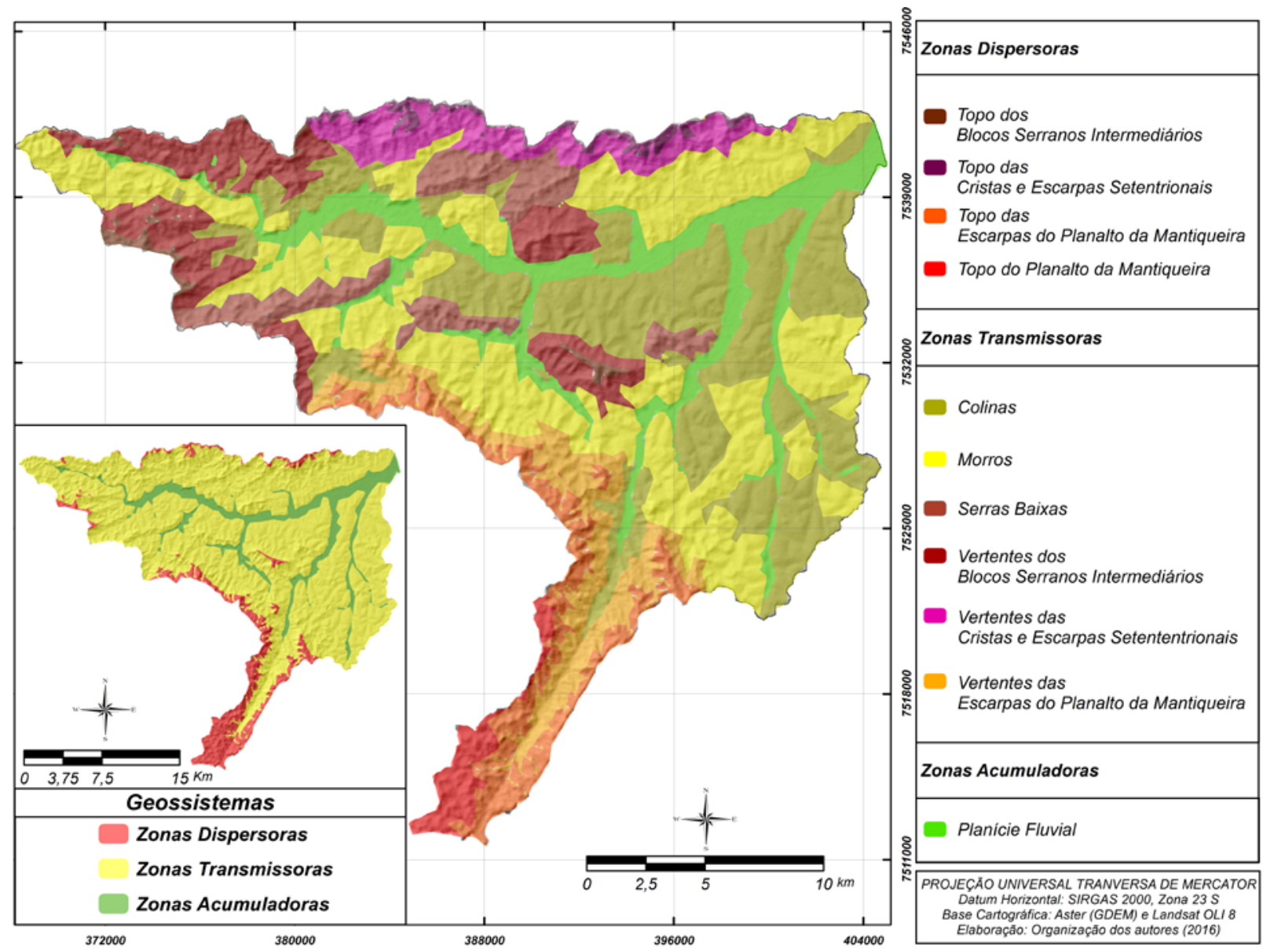

Figura 2 - Mapa dos Geossistemas da Sub-bacia Hidrográfica do Rio Mandu.

A geocronologia do substrato das Zonas Transmissoras varia do Arqueano ao Cenozoico, com formações gnáissicas, graníticas, migmatíticas, ortognáissicas e, nas áreas mais rebaixadas, coberturas cenozoicas (CPRM, 1998).

Ocorrem solos rasos, do tipo cambissolos e neossolos, mas predominam os de perfil profundo, sobretudo nas áreas de menor variação altimétrica, com argissolos, latossolos, nitossolos e solos com horizonte $\mathrm{B}$ mal drenado, do tipo glei, em pequenos vales de córregos e riachos (Ribeiro et al., 2016).

As Zonas Acumuladoras, onde há dissipação de matéria e energia, são as de menor declividade $(<6 \%)$ e altitudes, em geral, abaixo de $860 \mathrm{~m}$. O substrato é do Cenozoico, com depósitos aluvionares recentes e coberturas cenozoicas indiferenciadas (CPRM, 1998). Em relação aos solos, predominam os tipos com horizonte $\mathrm{B}$ mal drenados e gleissolos associados aos neossolos (Ribeiro et al., 2016).

A dinâmica de energia e materiais é influenciada pela distribuição de elementos naturais e antropizados na paisagem. Como síntese da distribuição espacial destes elementos foi elaborado o Mapa de Sistemas Antropo-Naturais (Figura 3), representando o tipo de uso e ocupação do solo.

A síntese das dimensões e porcentagens categorizadas como Sistemas Antrópicos e Sistemas Naturais está apesentada na figura 4. 


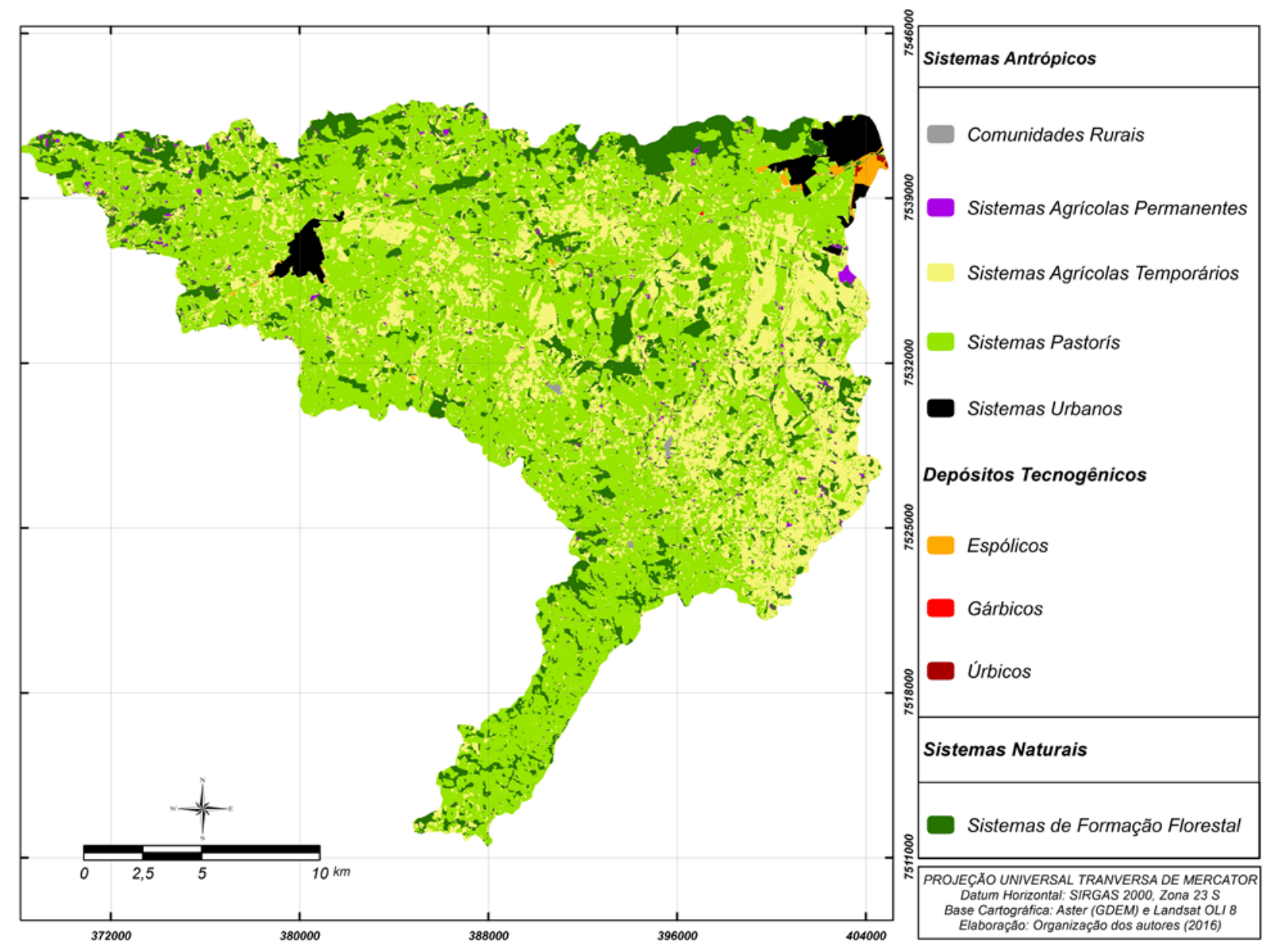

Figura 3 - Mapa de Sistemas Antropo-Naturais da Sub-bacia Hidrográfica do Rio Mandu.

\begin{tabular}{|c|c|c|c|c|}
\hline \multirow{2}{*}{\multicolumn{3}{|c|}{ Sistemas Antropo-Naturais }} & \multicolumn{2}{|c|}{ Área } \\
\hline & & & \multirow{2}{*}{$\begin{array}{c}\mathbf{k m}^{\mathbf{2}} \\
0,40\end{array}$} & \multirow{2}{*}{$\begin{array}{c}\text { \% } \\
0,08\end{array}$} \\
\hline \multirow[t]{8}{*}{ Sistemas Antrópicos } & \multicolumn{2}{|l|}{ Comunidades Rurais } & & \\
\hline & \multirow{3}{*}{ Depósitos Tecnogênicos } & Gárbicos & 0,02 & 0,01 \\
\hline & & Úrbicos & 0,17 & 0,03 \\
\hline & & Espólicos & 2,10 & 0,42 \\
\hline & \multicolumn{2}{|c|}{ Sistemas Agrícolas Permanentes } & 5,00 & 1,00 \\
\hline & \multicolumn{2}{|c|}{ Sistemas Agrícolas Temporários } & 123,46 & 24,70 \\
\hline & \multicolumn{2}{|l|}{ Sistemas Pastoris } & 294,68 & 58,94 \\
\hline & \multicolumn{2}{|l|}{ Sistemas Urbanos } & 10,00 & 2,00 \\
\hline Sistemas Naturais & \multicolumn{2}{|c|}{ Sistemas de Formação Florestal } & 64,17 & 12,82 \\
\hline \multicolumn{3}{|l|}{ Total } & 500,00 & 100,00 \\
\hline
\end{tabular}

Figura 4 - Área ocupada por cada um dos Sistemas Antropo-Naturais.

Os Sistemas Antrópicos classificados foram: as Comunidades Rurais (Sertãozinho, em Borda da Mata, Pântano, em Estiva, e Pântano São José, em Pouso Alegre); os Sistemas Agrícolas Permanentes com plantios de café e de eucalipto; os Sistemas Agrícolas Temporários, com culturas temporárias e solo exposto devido ao preparo para cultivo; os Sistemas Pastoris, áreas com pastos; os Sistemas Urbanos, sede do Município de Borda da Mata e parte da sede do
Município de Pouso Alegre; e os Depósitos Tecnogênicos: espólicos, gárbicos e úrbicos. Os Sistemas Naturais estão representados pelos Sistemas de Formação Florestal, do tipo estacional semidecidual, do bioma Mata Atlântica (Machado \& Silva, 2010), que cobrem 12,82\% da sub-bacia, muito aquém do previsto pelo Código Florestal. É marcante o descumprimento das APP e RL e isto é relevante também para a produtividade das 
áreas agrícolas, uma vez que áreas com maior abundância de matas nativas sofrem menos com pragas e, em média, produzem mais.

O aumento da produtividade está conectado à polinização pelos insetos, diminuição da erosão pelo escoamento superficial, aumento do teor de matéria orgânica e de umidade e melhoria da estrutura do solo, entre outros fatores.

Assim, na sub-bacia os serviços ecossistêmicos prestados pela fauna e flora estão seriamente comprometidos pela redução e degradação das áreas de vegetação nativa.

Para Priess et al. (2007), os serviços dados pelos insetos são responsáveis por aumentos na produtividade, qualidade e estabilidade de até $70 \%$ na produção agrícola mundial. Pois, as visitas dos polinizadores não só movem o pólen entre os indivíduos, mas também aumentam a quantidade total de pólen depositado nos estigmas de flores, sendo que ambos são reconhecidos por aumentar a quantidade e a qualidade das culturas.

Tais autores calcularam o impacto da perda de florestas sobre a produtividade em cafezais no sul de Minas Gerais.

A partir da magnitude do desmatamento em curso, os serviços de polinização deverão diminuir de forma contínua e reduzir diretamente a produção de café em até $18 \%$, e a receita líquida por ha em até 14\% até 2027. Além disto, a polinização pelos insetos, em especial pelas abelhas, está comprometida, não só pela ausência de APP e RL, mas também pela utilização em larga escala dos agroquímicos (Londres, 2011).

Estudo sobre a distribuição das abelhas nativas na região sul de Minas Gerais constatou que paisagens com limiares menores do que 25\% de área de mata nativa, tendem a extinção destes polinizadores, afetando o serviço ecossistêmico (Raniero, 2013).

Esta constatação é relevante, já que apenas $12,82 \%$ da área da sub-bacia ainda possui vegetação nativa (Figura 4).

O desmatamento também intensificou os processos de degradação dos solos e dos recursos hídricos. De maneira geral, Magalhães Jr. \& Diniz (2005) apontaram que a dinâmica da paisagem é intensa na sub-bacia, com ravinamentos profundos e cicatrizes de deslizamento associadas à incisão de canais fluviais nos amplos anfiteatros erosivos. Isto explicita a magnitude dos processos morfodinâmicos, que resultam em degradação dos recursos naturais locais.

A partir da observação da morfodinâmica, foi possível elaborar uma síntese da combinação de componentes da paisagem que intensificam a degradação ambiental. A combinação entre solo, relevo e uso do solo que mais resultou em impactos intrínsecos foi a de solos rasos, do tipo cambissolos, em relevos muito dissecados, usados para pastagens (45 locais com feições de rastejo).

O uso inadequado com culturas temporárias e solos expostos também foi relevante para a degradação de sistemas naturalmente mais estáveis em 34 locais.

Nestes, apesar dos solos serem mais profundos, do tipo latossolos, com erodibilidade baixa ou muito baixa (Ribeiro et al., 2016), houve registros de ravinamentos.

No total, foram identificadas 191 ocorrências de rastejos e ravinas, predominando os rastejos, cuja associação com os atributos ambientais é detalhada na tabela 1.

A partir dos processos morfodinâmicos, foi possível identificar as áreas estáveis e as potencialmente instáveis, conforme o tipo de solo e a dissecação do relevo, frente ao uso (Figura 5).

Tabela 1 - Número de pontos de ocorrência de rastejos e ravinas conforme os atributos ambientais: solo, dissecação do relevo e tipo de uso.

\begin{tabular}{l|l}
\hline Atributos Ambientais & $\begin{array}{l}\text { Número de } \\
\text { Ocorrências }\end{array}$ \\
\hline Solo & \\
\hline Nitossolo Háplico & 4 \\
\hline Argissolo Vermelho & 5 \\
\hline Latossolo Vermelho-Amarelo & 34 \\
\hline Argissolo Vermelho-Amarelo & 42 \\
\hline Latossolo Vermelho & 45 \\
\hline Cambissolo Háplico & 61 \\
\hline Dissecação & \\
\hline Baixa & 1 \\
\hline Média & 32 \\
\hline Forte & 66 \\
\hline Muito Forte & 92 \\
\hline Tipo de Uso & \\
\hline Área Urbana & 1 \\
\hline Culturas Temporárias & 37 \\
\hline Solo Exposto & 43 \\
\hline Pastagem & 110 \\
\hline
\end{tabular}




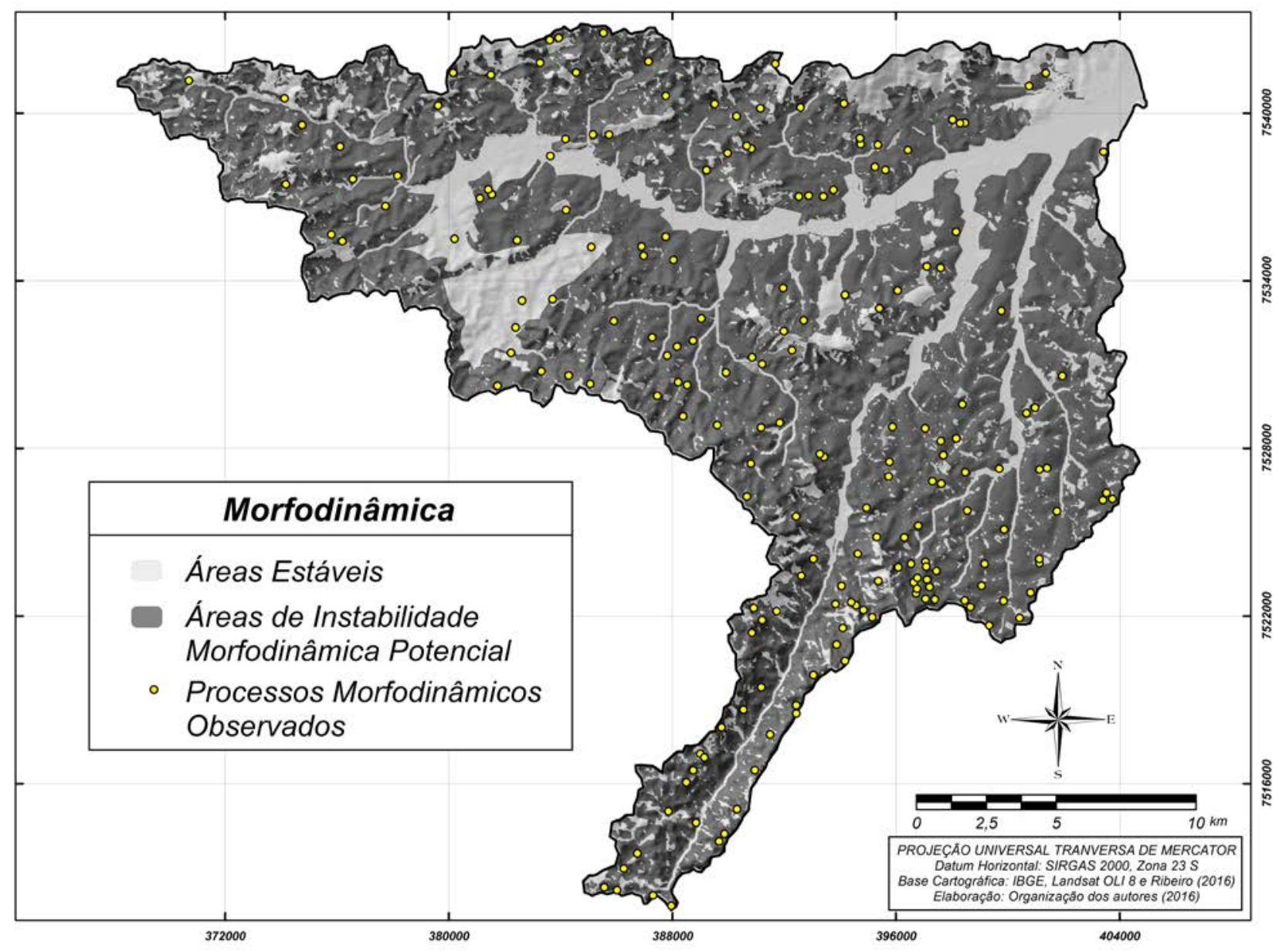

Figura 5 - Mapa Morfodinâmico da Sub-bacia Hidrográfica do Rio Mandu.

A partir dos mapeamentos do geossistema, dos sistemas antropo-naturais e da morfodinâmica foi apreendido o funcionamento da paisagem quanto aos fluxos de materiais e de energia.

As Zonas de Dispersão condicionam fluxos de matéria e energia mais ou menos intensos para os demais sistemas. São os espaços nos quais usos antrópicos do solo, além de acarretarem impactos intrínsecos, também afetam significativamente os demais geossistemas.

Nas Zonas Transmissoras ocorre a maioria dos processos degradacionais dos solos, com movimentações pela erosão e por escorregamentos do tipo rastejo. A intensidade de tais processos cresce conforme aumenta a dissecação do relevo e diminui a espessura do solo. Os mais elevados graus de vulnerabilidade à erosão hídrica encontrados por Ribeiro et al. (2016) coincidem com esta zona. Nos morros e colinas, há solos com perfis espessos, indicando predomínio pretérito da pedogênese sobre a morfogênese. Todavia, a dinâmica recente da paisagem tem acelerado esculturação do relevo pelos usos antrópicos do solo.

Nas Zonas Acumuladoras predominam processos gradacionais. Os principais impactos, como o assoreamento dos cursos d'água, a modificação do padrão fluvial, a diminuição da disponibilidade e qualidade da água e suas consequências à fauna, à flora e ao homem, são condicionados, dominantemente, pelas dinâmicas da paisagem dos outros dois sistemas. Diante disso, emerge a necessidade de preservação da vegetação do entorno dos corpos d'água, necessária para a absorção do excedente de material e energia.

A partir da síntese do grau de impacto e da capacidade de reação e absorção de cada fração da paisagem, conforme o fluxo de materiais e energia, foi feita a Carta de Estado Ambiental da sub-bacia (Figura 6) com a quantificação das áreas correspondentes a cada classe (Figura 7).

As áreas dos sistemas de formações florestais e as estabelecidas como APP de entorno de nascentes e cursos d'água por Brasil (2012), com vegetação nativa preservada, foram classificadas como Estáveis. Já, as APP que possuem outros usos foram classificadas 
como Críticas, pois são áreas de elevado interesse ambiental e condicionam mudanças estruturais no funcionamento dos sistemas. Também classificadas como Críticas foram as áreas urbanas e as de solo exposto, uma vez que

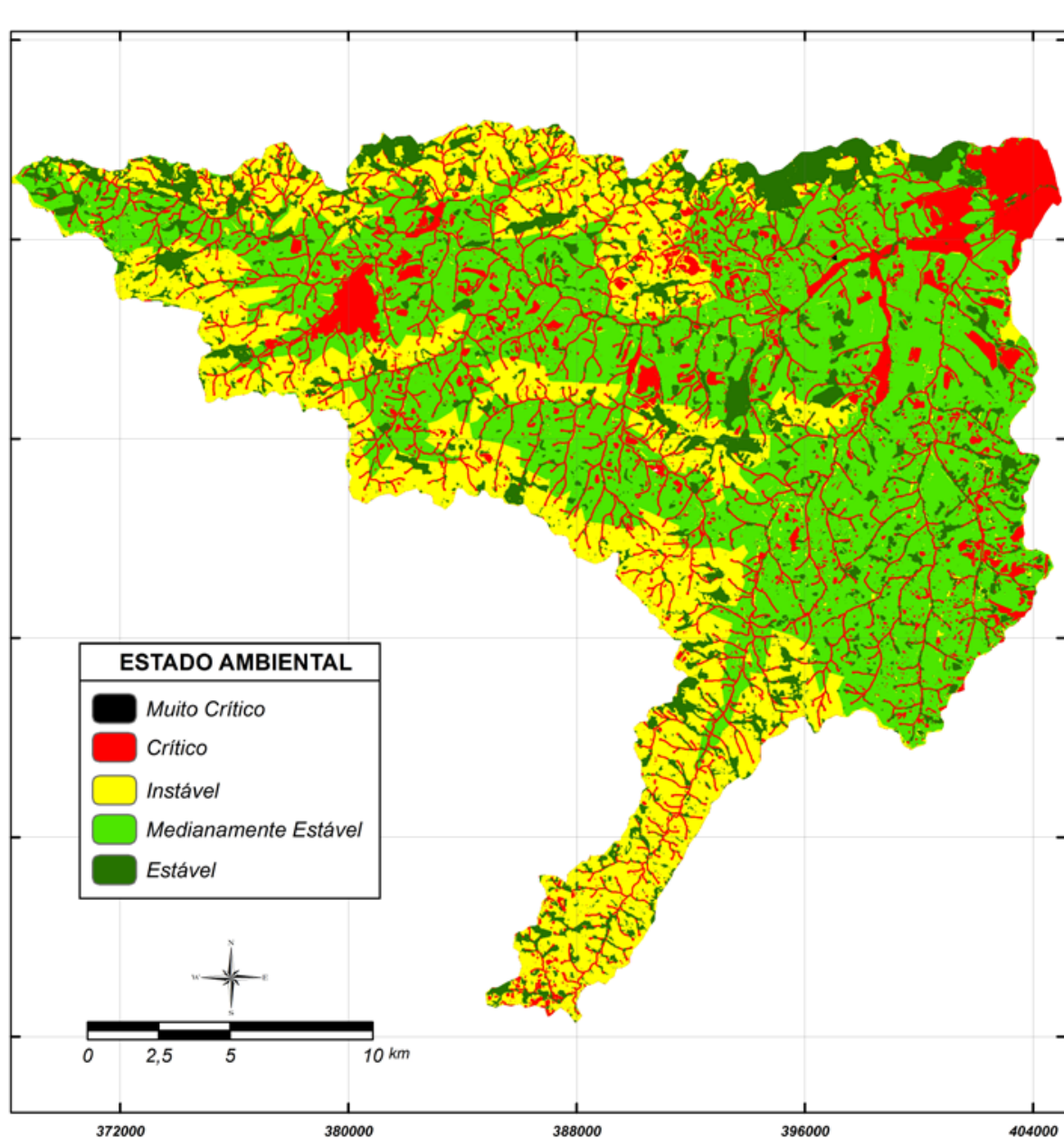

ocorreram alterações significativas na estrutura de funcionamento do sistema e perderam o potencial natural. Precisam, portanto, da adoção de medidas mitigadoras dos impactos ambientais.

Figura 6 - Mapa de Estado Ambiental da Sub-bacia Hidrográfica do Rio Mandu.

\begin{tabular}{|c|c|c|}
\hline \multirow{2}{*}{ Estado Ambiental } & \multicolumn{2}{|c|}{ Área } \\
\cline { 2 - 3 } & $\mathbf{k m}^{\mathbf{2}}$ & $\mathbf{\%}$ \\
\hline Muito Crítico & 0,02 & 0,01 \\
\hline Crítico & 86,98 & 17,39 \\
\hline Instável & 130,00 & 26,00 \\
\hline Medianamente Estável & 218,83 & 43,78 \\
\hline Estável & 64,17 & 12,82 \\
\hline Total & 500,00 & 100,00 \\
\hline
\end{tabular}

Figura 7 - Área total de cada classe de Estado Ambiental.

As áreas de planícies fluviais, colinas e morros com sistemas agrícolas temporários ou pastoris foram classificadas como Medianamente Estáveis, pois não apresentam alterações estruturais que tenham modificado o seu potencial natural. Todavia, a ausência de manejo adequado pode comprometer o potencial de uso futuro. Porém, a adoção de práticas de manejo conservacionistas adequadas garantiria a utilização destas parcelas por várias

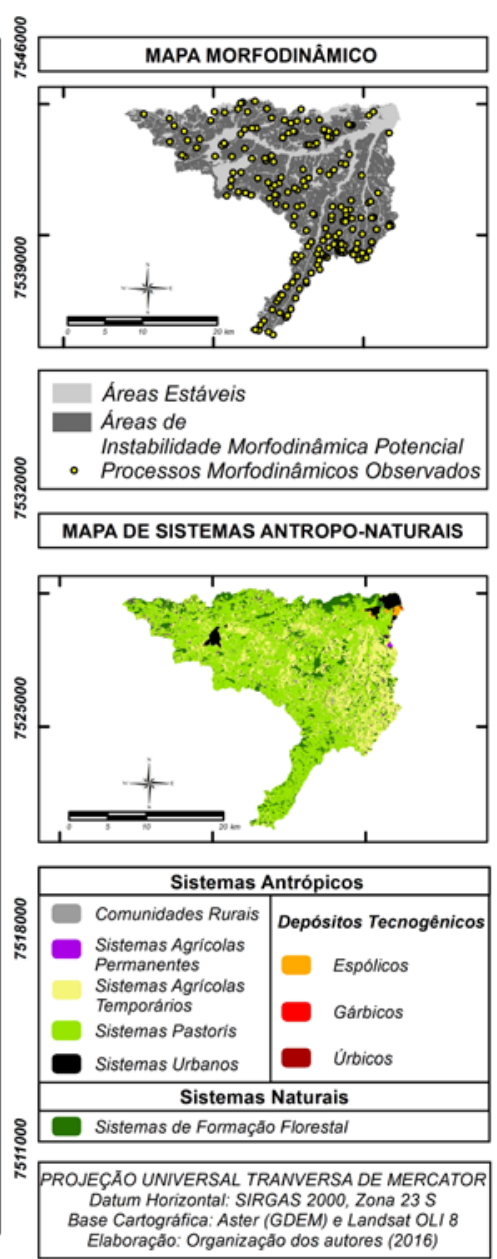

Elaboraçăa: Organizaçẩo dos autores (2016) gerações com baixo custo de manutenção da sustentabilidade (Ribeiro et al., 2016).

As áreas com dissecação forte e muito forte de topos, das vertentes de cristas e escarpas de formações serranas e serras baixas com sistemas agrícolas permanentes ou temporários ou pastoris foram classificadas como Instáveis, devido à quantidade de solos degradados nestes segmentos da paisagem, que indicam usos não adequados e função geoecológica alterada. 
O Depósito Tecnogênico Gárbico, do antigo "lixão", de Pouso Alegre, localizado próximo ao rio Mandu, foi classificado como de Estado Ambiental Muito Crítico, em razão dos danos ambientais causados pela disposição

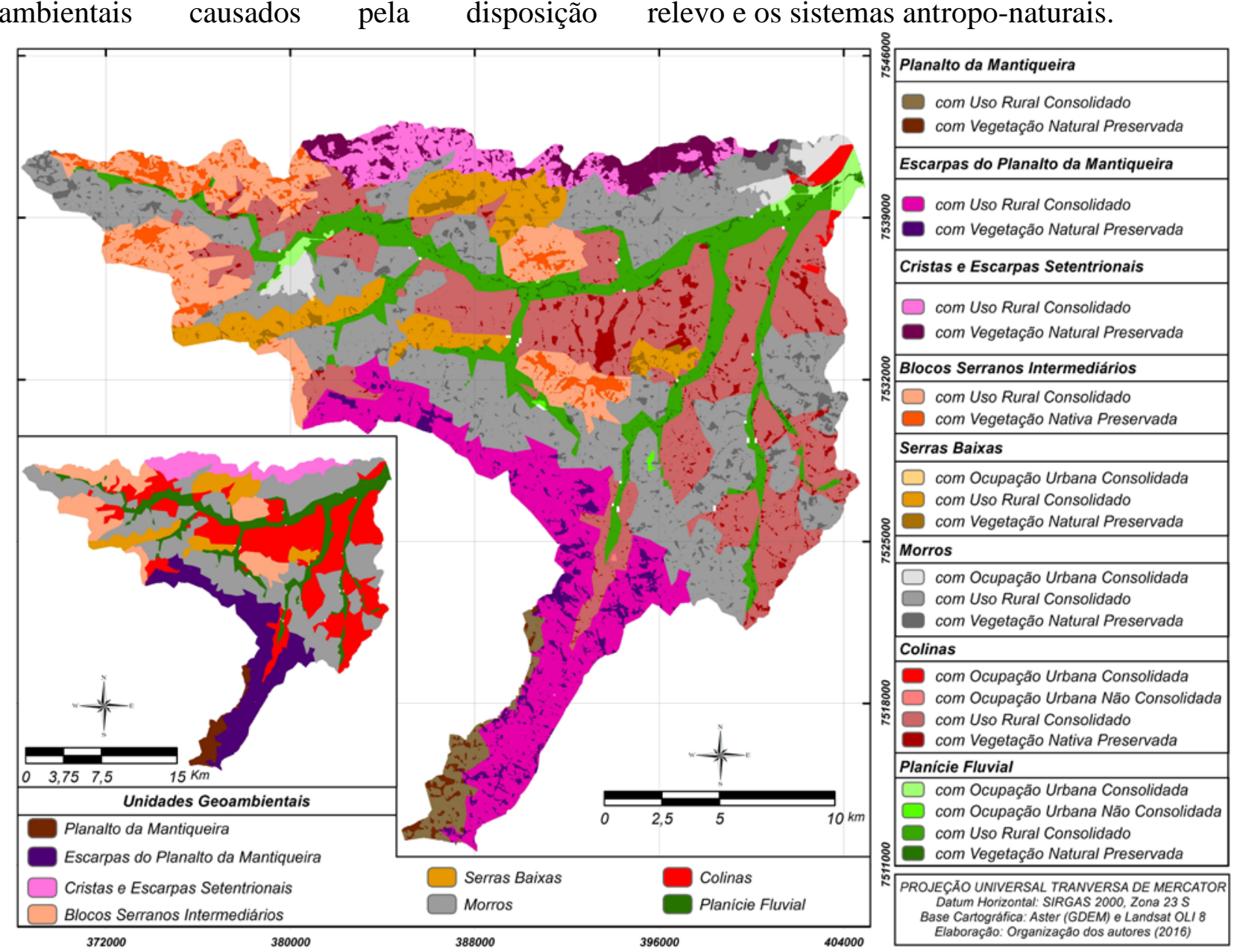

inadequada e indevida de lixo. Na sequência, como síntese da paisagem, foi elaborado o Mapa de Unidades Geoambientais (Figura 8), considerando as Unidades Morfológicas do relevo e os sistemas antropo-naturais.

Figura 8 - Mapa de Unidades Geoambientais da Sub-bacia Hidrográfica do Rio Mandu.

No mapa de Unidades Geoambientais, as oito unidades geomorfológicas foram subdivididas de acordo com os usos do solo. Assim, além do relevo, quatro tipos de subunidades compõem as Unidades Geoambientais: (1) Ocupação Urbana Consolidada, que são as áreas urbanas e os depósitos tecnogênicos espólicos, gárbicos e úrbicos, que têm funcionalidade e gênese vinculadas ao ambiente urbano; (2) Ocupação Urbana Não Consolidada representada pelas pequenas comunidades rurais; (3) Uso Rural Consolidado que corresponde às culturas temporárias, ao plantio de café e eucalipto e ao solo exposto em fase de preparação para o plantio e (4) Vegetação Natural Preservada, referente a fragmentos de floresta nativa preservada.

Por fim, o Mapa de Zoneamento Geoambiental (Figura 9), foi elaborado a partir da dinâmica dos fluxos de materiais e de energia, influenciada por fatores naturais e antrópicos, e da degradação ambiental resultante nas unidades da paisagem.

Para tanto, foram usados os materiais cartográfico de Unidades Geossistêmicas, Estado Ambiental e Unidades Geoambientais, frente ao conjunto de normas que regulam o uso do solo no local, expressas nas legislações municipais, estadual e federal.

Desta maneira foram obtidas cinco zonas e onze subzonas, com proposições específicas, conforme as características ambientais e as necessidades de preservação com vistas à sustentabilidade. A figura 10 apresenta, em $\mathrm{km}^{2}$ e porcentagem, as áreas de cada Zona Geoambiental da sub-bacia.

As Zonas de Proteção Ambiental foram divididas em: (1) Com Uso Adequado, as que estão com mata nativa preservada e (2) Com 
Uso Inadequado, as que, por lei, deveriam estar protegidas. Neste caso, estão as APP, o Corredor Ecológico e a Reserva Biológica de
Pouso Alegre, que são áreas de interesse coletivo para preservação da flora e fauna e de serviços eco e geossistêmicos.

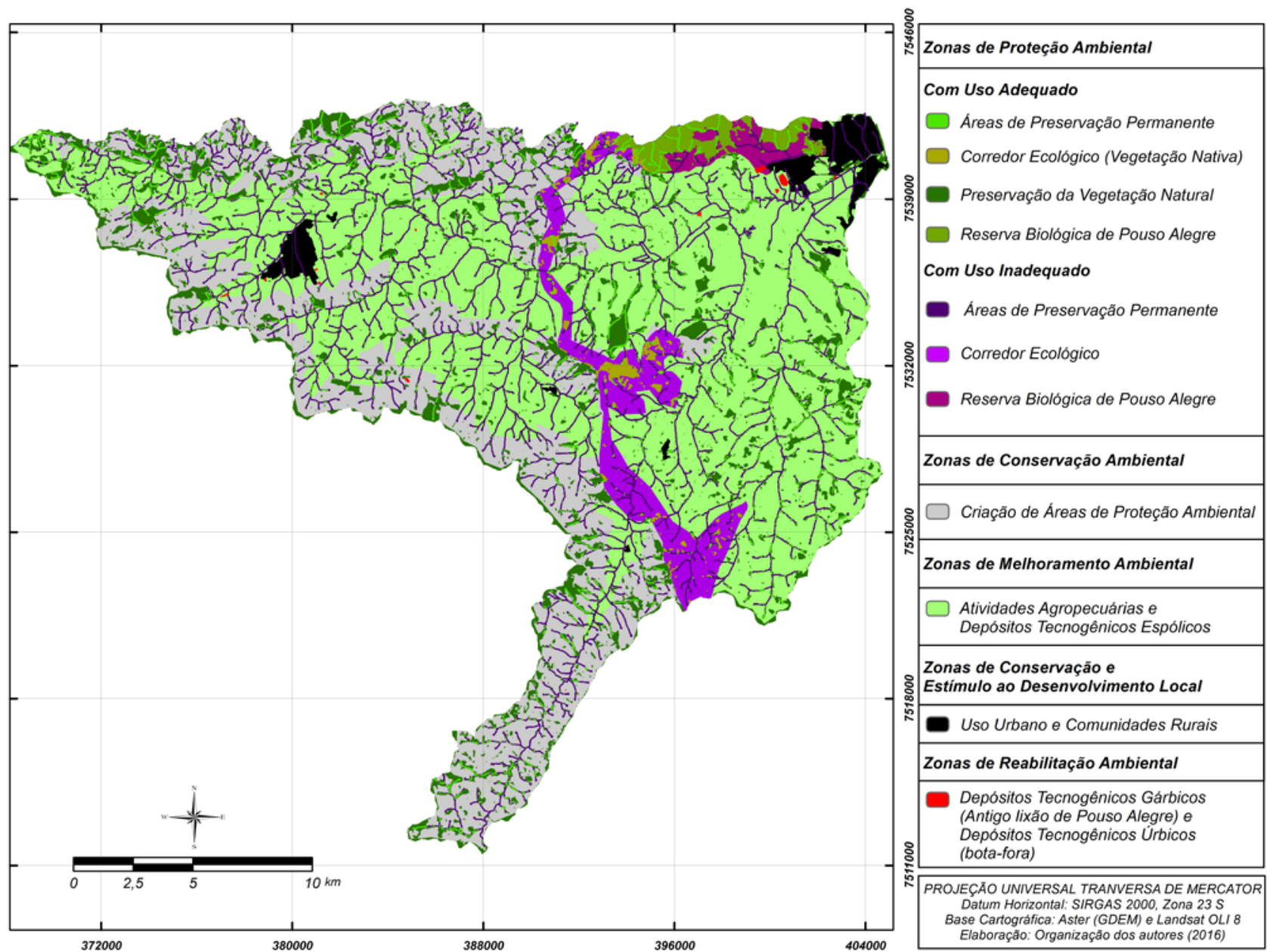

Figura 9 - Mapa de Zoneamento Geoambiental da Sub-bacia Hidrográfica do Rio Mandu.

\begin{tabular}{|l|l|c|c|}
\hline \multicolumn{1}{|c|}{ Zonas } & Área (km²) & Área (\%) \\
\hline \multirow{4}{*}{ ZPA } & COM USO ADEQUADO & 71,1 & 13,9 \\
\cline { 2 - 4 } & Áreas de Preservação Permanente & 13,7 & 2,7 \\
\cline { 2 - 4 } & Corredor Ecológico & 3,8 & 0,7 \\
\cline { 2 - 4 } & Preservação da Vegetação Natural & 47,2 & 9,3 \\
\cline { 2 - 4 } & Reserva Biológica de Pouso Alegre & 6,4 & 1,2 \\
\cline { 2 - 4 } & COM USO INADEQUADO & 76,3 & 15,2 \\
\cline { 2 - 4 } & Efetivação das Áreas de Preservação Permanente & 49,0 & 9,8 \\
\cline { 2 - 4 } & Efetivação do Corredor Ecológico & 22,6 & 4,5 \\
\cline { 2 - 4 } & Efetivação da Reserva Biológica de Pouso Alegre & 4,7 & 0,9 \\
\hline ZCA & Criação de Áreas de Proteção Ambiental & 114,0 & 22,7 \\
\hline ZMA & Atividades Agropecuárias e Depósitos Tecnogênicos Espólicos & 227,3 & 45,3 \\
\hline ZCEDL & Uso Urbano & 10,9 & 2,1 \\
\hline ZRA & Depósitos Tecnogênicos Gárbicos e bota-fora. & 0,4 & 0,8 \\
\hline TOTAL & & 500,0 & 100,0 \\
\hline
\end{tabular}

ZPA = Zonas de Proteção Ambiental, ZCA = Zonas de Conservação Ambiental, ZMA = Zonas de Melhoramento Ambiental, ZCEDL = Zonas de Conservação e Estímulo ao Desenvolvimento Local, ZRA = Zonas de Reabilitação Ambiental.

Figura10 - Área total de cada classe de Zona Geoambiental.

As Zonas de Conservação Ambiental são, por sua vez, locais que necessitam de controle dos usos do solo e, necessariamente, da aplicação de técnicas de manejo conservacionistas. A instituição de APA nestas zonas é pertinente, uma vez que já têm uso e 
ocupação humana consolidados, mas que cumpriria função importante para preservação e uso sustentável dos recursos naturais da subbacia.

Nas Zonas de Melhoramento Ambiental, se mantidos os usos e melhoradas as condições de manejo, estas áreas podem ser usadas por longos períodos. Estas áreas são, dominantemente, usadas para atividades agropecuárias, mas incluem também os Depósitos Tecnogênicos Espólicos. Estes depósitos demandam medidas específicas de infraestrutura e de mitigação dos impactos ambientais.

As Zonas de Conservação e Estímulo ao Desenvolvimento Local são as áreas urbanas dos municípios e das comunidades rurais. Mesmo com Estado Ambiental Crítico, pelas alterações na dinâmica natural do sistema, estão consolidadas e precisam de planejamento para o uso apropriado e a conservação de determinados espaços e recursos, com vistas à melhoria da qualidade de vida.

Por fim, as Zonas de Reabilitação Ambiental são representadas pelo depósito tecnogênico gárbico, o antigo "lixão" de Pouso Alegre, e pelos Depósitos Tecnogênicos Úrbicos (botafora).

O caso mais grave é o do “lixão”, área prioritária em termos de recuperação ambiental, pelo potencial de danos à saúde coletiva de seres humanos e ao ambiente como um todo.

\section{CONSIDERAÇÕES FINAIS}

Para síntese da dinâmica natural diante do uso do solo, a compartimentação geomorfológica foi adotada em primeiro plano. Pois permite discriminar dinâmicas específicas e características das diferentes unidades. Porém, para abarcar a dinâmica natural da paisagem foi essencial a inclusão das trocas sistemáticas de materiais e energia, conforme $o$ conceito de geossistema.

Posteriormente, a incorporação das transformações antrópicas pelos usos do solo permitiu identificar a dinâmica da paisagem atual, considerando o estado de preservação ou degradação.

As etapas descritas, aliadas às aspirações de conservação do provimento de serviços ambientais pelos geossistemas locais, expressas em normativas das distintas esferas administrativas, permitiram apontar a adequação de usos pelo Zoneamento Geoambiental, que pode subsidiar a gestão ambiental da Sub-Bacia Hidrográfica do Rio Mandu.

Em termos gerais, houve constatação de que apenas 12,82\% da área natural de floresta ainda está preservada, correspondendo às áreas com dinâmica estável. Dos demais 87,18\%, em cerca da metade, 43,78\%, não ocorreram alterações que modificaram o potencial natural, mas, sem adoção de práticas de manejo conservacionista o potencial de uso futuro está ameaçado. Para os demais 43,40\%, são necessários planejamentos específicos para reabilitação e recuperação ambiental.

Como síntese de recomendações, o Zoneamento Geoambiental apontou a necessidade de recuperação urgente das Zonas de Reabilitação Ambiental e efetivação das Zonas de Proteção Ambiental e adoção de medidas restritivas quanto ao uso do solo nas Zonas de Conservação Ambiental. Ademais, nas Zonas de Melhoramento Ambiental e Zonas de Conservação e Estímulo ao Desenvolvimento Local, ficou evidente a necessidade de planejamentos que considerem a adoção de técnicas conservacionistas, para assegurar a produtividade e a sustentabilidade em longo prazo.

\section{REFERÊNCIAS}

BERTRAND, G. Paisagem e geografia física global: esboço metodológico. Caderno de Ciências da Terra, n. 13, p. 127. 1971.

BRASIL. Ministério do Meio Ambiente. SNUC - Sistema Nacional de Unidades de Conservação da Natureza: Lei $n^{\circ}$ 9.985, de 18 de julho de 2000; Decreto $\mathrm{n}^{0} 4.340$, de 22 de agosto de 2002; Decreto $\mathrm{n}^{\circ}$ 5.746, de 5 de abril de 2006. Plano Estratégico Nacional de Áreas Protegidas: Decreto $\mathrm{n}^{\circ}$ 5.758, de 13 de abril de 2006 / Ministério do Meio Ambiente. - Brasília: MMA/SBF, 2011. 76 p.

BRASIL. Novo Código Florestal Brasileiro. 2012. Lei $n^{0}$
12.651, de 25 de maio de 2012. Disp. em: <http://www.planalto.gov.br/ccivil_03/_ato20112014/2012/lei/112651.htm>. Acesso em: 06ago2016.

CPRM - COMPANHIA DE PESQUISA DE RECURSOS MINERAIS - SERVIÇO GEOLÓGICO DO BRASIL. Carta Geológica Guaratinguetá, Escala 1: 250.000. São Paulo: Companhia de Pesquisa de Recursos Minerais, 1998.

DIAS, R.L. \& OLIVEIRA, R.C. Análise das Paisagens do Litoral Sul do Estado de São Paulo. Sociedade \& Natureza, v. 24, n. 3, p. 505-518, 2012.

ESRI. ArcGis 10.2.2 for Desktop. Redlands, California: 
Environmental Systems Research Insitute. 2014

ENVI. 5.0 - Visual Information Solutions. Boulder, Colorado: Exelis. 2012.

GIGLIOTTI, M.S. Zoneamento Geoambiental da região da baixada santista - SP como subsídio ao uso e ocupação das terras. Campinas, 2010. 175p. Dissertação (Mestrado em Geografia) - Instituto de Geociências, Universidade Estadual de Campinas.

GOUVÊA, O.M. A História de Pouso Alegre. Pouso Alegre. Gráfica Amaral, 2 ed., 2004.

IBGE - INSTITUTO BRASILEIRO DE GEOGRAFIA E ESTATÍSTICA. Carta Topográfica de Conceição dos Ouros folha SF23-Y-B-II-3, Escala 1:50.000. Rio de Janeiro: IBGE, 1971(a).

IBGE - INSTITUTO BRASILEIRO DE GEOGRAFIA E ESTATÍSTICA. Carta Topográfica de Pouso Alegre folha SF23-Y-B-II-1, Escala 1:50.000. Rio de Janeiro: IBGE, 1971(b).

IBGE - INSTITUTO BRASILEIRO DE GEOGRAFIA E ESTATÍSTICA. Carta Topográfica de Santa Rita de Caldas folha SF23-Y-B-I-1, Escala 1:50.000. Rio de Janeiro: IBGE, 1972 (a).

IBGE - INSTITUTO BRASILEIRO DE GEOGRAFIA E ESTATÍSTICA. Carta Topográfica de Ipuiuna folha SF23Y-B-I-2, Escala 1:50.000. Rio de Janeiro: IBGE, 1972 (b).

IBGE - INSTITUTO BRASILEIRO DE GEOGRAFIA E ESTATÍSTICA. Carta Topográfica de Borda da Mata folha SF23-Y-B-I-4, Escala 1:50.000. Rio de Janeiro: IBGE, 1972 (c).

LONDRES, F. Agrotóxicos no Brasil: um guia para ação em defesa da vida. 1.ed. Rio de Janeiro: Assessoria e Serviços a Projetos em Agricultura Alternativa, 2011.

MACHADO, M.F. \& SILVA, S.F. Geodiversidade: Adequabilidade/Potencialidades e Limitações Frente ao Uso e à Ocupação. In: MACHADO, M.F., SILVA, S.F. (Org.), Geodiversidade do Estado de Minas Gerais. Belo Horizonte: Ministério de Minas e Energia, Secretaria de Geologia, Mineração e Transformação Mineral e Serviço Geológico do Brasil, p. 49-94, 2010.

MAGALHÃES Jr.; A.P.; DINIZ, A.A. Padrões e Direções de Drenagem na Bacia do Rio Sapucaí - Sul de Minas Gerais. GEONOMOS, v. 5, n. 2, p. 29-32, 1997.

MAGALHÃES Jr. A.P. \& DINIZ, A.A.. Morfodinâmica Fluvial Cenozoica em Zonas de Contato entre Faixas Móveis e "Cunhas Tectônicas" na Região Sul de Minas Gerais. GEONOMOS, v. 13, n. 1, p. 59-74, 2005.

MELLO, C.R.; SÁ, M.A.C.; CURI, N.; MELLO, J.M.; VIOLA, M.R.; SILVA, A.M. Erosividade mensal e anual no Estado de Minas Gerais. Pesquisa Agropecuária Brasileira, v. 42, n. 4, p. 537-545, 2007.

NATIONAL AERONAUTICS AND SPACE ADMINISTRATION - NASA. ASTER GDEM: Advanced Spaceborne Thermal and Reflection Radiometer. Estados Unidos, 2015.
PELOGGIA, A.U.G. A cidade, as vertentes e as várzeas: a transformação do relevo pela ação do homem no município de São Paulo. Revista do Departamento de Geografia, v. 16, p. 24-31, 2011.

POUSO ALEGRE. Secretaria de Planejamento. Plano Diretor Municipal de Pouso Alegre/MG. Pouso Alegre: Prefeitura Municipal de Pouso Alegre, 2008.

PRIESS, J.A.; MIMLER, M; KLEIN, A.M., SCHWARZE, S.; TSCHARNTKE, T.; STEFFAN-DEWENTER, I. Linking deforestation scenarios to pollination services and economic returns in coffee agroforestry systems. Ecology Applied, v.17, p. 407- 417, 2007.

RANIERO, M. O efeito da paisagem na subtribo de abelhas Euglossina (Hymenoptera: Apidae). Dissertação (Mestrado em Ecologia e Tecnologia Ambiental). Alfenas, 2013. 54p. UNIFAL-MG

RIBEIRO, A.S.; MINCATO, R.L.; CURI, N.; KAWAKUBO, F.S. Vulnerabilidade Ambiental à Erosão Hídrica em uma Sub-bacia Hidrográfica pelo Processo Analítico Hierárquico. Revista Brasileira de Geografia Física, v. 9, n. 1, p. 016031, 2016.

RODRIGUES, C. A teoria geossistêmica e suas contribuições aos estudos geográficos e ambientais. Revista do Departamento de Geografia, n. 14, p. 69-77, 2001.

RODRIGUEZ, J.M.M. Análise e síntese da abordagem geográfica da pesquisa para o planejamento ambiental. Revista do Departamento de Geografia da FFLCH/USP, v. 9, 1994.

RODRIGUEZ, J.M.M.; SILVA, E.D.; CAVALCANTI, A.P.B. Geoecologia da paisagem: uma visão ecossistêmica da análise ambiental. Fortaleza: EDUFC, 2 ed., 2007.

ROSS, J.L.S. O Registro Cartográfico dos Fatos Geomórficos e a Questão da Taxonomia do Relevo. Revista do Departamento de Geografia (USP), v. 6, 1992.

ROSS, J.L.S. Análise empírica da fragilidade dos ambientes naturais e antropizados. Revista do Departamento de Geografia (USP), v. 8, p. 63-74, 1994.

ROSS, J.L.S. Ecogeografia do Brasil: subsídios para planejamento ambiental. São Paulo: Oficina de Textos, 2009.

SOTCHAVA, V.B.O. Estudo de Geossistemas. Métodos em Questão, n. 16, p. 1-52, 1977.

SPAROVEK, G.; VAN LIER, Q.J.; DOURADO NETO, D. Computer assisted Koeppen climate classification: a case study for Brazil. International Journal of Climatology, v. 27, n. 2, p. 257-266, 2007.

TRICARD, J. Ecodinâmica. Rio de Janeiro: FIBGE/SUPREN, 1977. 